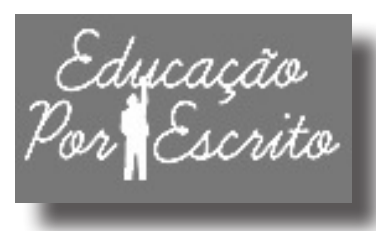

ARTIGO

\section{Editor}

Maria Inês Côrte Vitoria PUCRS, RS, Brasil

\section{Equipe Editorial}

Pricila Kohls dos Santos PUCRS, RS, Brasil

Marcelo Oliveira da Silva PUCRS, RS, Brasil

Carla Spagnolo PUCRS, RS, Brasil Rosa Maria Rigo PUCRS, RS, Brasil

\title{
Contribuições para uma internacionalização da educação superior desde e para América Latina. A experiência da UNILA e da ELAM
}

\section{Contributions to an internationalization of higher education from and to Latin America. The experience of UNILA and ELAM}

\section{Maria Julieta Abba ${ }^{a}$, Berenice Corsettib}

RESUMO: O trabalho tem como objetivo refletir sobre uma internacionalização da educação superior desde e para a América Latina, mediante o estudo das experiências da Universidade Federal para a Integração LatinoAmericana (UNILA), localizada em Foz de Iguaçu, Brasil, e da Escola Latino-americana de Medicina (ELAM), localizada em Havana, Cuba. Deste modo, buscamos problematizar a temática da internacionalização através da tensão entre duas perspectivas teóricas: uma hegemônica e outra em construção. Trata-se de um estudo exploratório e descritivo, desenvolvido a partir da análise de documentos e da produção bibliográfica sobre a internacionalização, a UNILA e a ELAM. O texto está organizado em quatro partes. Na primeira, analisamos diversas perspectivas da internacionalização da educação superior, detectadas mediante a revisão bibliográfica da pesquisa. Em segundo lugar, caracterizamos uma perspectiva da internacionalização, que consideramos em construção, formulada desde e para a América Latina. Num terceiro momento, apresentamos duas experiências de internacionalização que se inserem nesta última perspectiva emergente. Finalmente, expomos algumas considerações e reflexões sobre o trabalhado ao longo do texto, e apontamos os principais desafios a serem enfrentados por estas duas instituições no que diz respeito à promoção da internacionalização desde e para América Latina.

Palavras-chave: internacionalização; América Latina; experiências; ELAM; UNILA.

ABSTRACT: The work aims to reflect on the internationalization of higher education from and for Latin America, by studying the experiences of Universidade Federal para a Integração Latino-Americana (UNILA), localized in Foz do Iguaçu, Brazil, and the Escola Latino-americana de Medicina (ELAM), localized in Havana,

\footnotetext{
a Mestre em Políticas y Administración de la Educación (UNTREF). Doutoranda no Programa de Pós-Graduação em Educação da Universidade do Vale do Rio dos Sinos - UNISINOS. Bolsista do Programa Estudante Convenio da Pós-graduação da CAPES. <mjulieta.abba@gmail.com>.

b Doutora em Educação. Professora no Programa de Pós-Graduação em Educação da Universidade do Vale do Rio dos Sinos - UNISINOS. < bcorsetti@unisinos.br>.
} 
Cuba. Thus, we seek to discuss the issue of internationalization through the tension between two theoretical perspectives: one hegemonic and another under construction. It is an exploratory and descriptive study, developed from the analysis of documents and bibliographic production on internationalization, UNILA and ELAM. The text is organized into four parts. At first, we analyze different perspectives of the internationalization of higher education, identified by literature review of the research. Secondly, we characterize a perspective of internationalization, which we consider in construction, formulated to and from Latin America. In the third place, we present two international experiences, which fall in the latter emerging perspective. Finally, we expose some considerations and reflections on what worked throughout the text, and identify the main challenges to be faced by these two institutions regarding the promotion of internationalization to and from Latin America.

Keywords: internationalization; Latin America; experiences; UNILA; ELAM.

\section{Introdução}

Estas ste trabalho forma parte de uma pesquisa doutoral em construção, realizada no Programa de Pós-graduação da Universidade do Vale do Rio dos Sinos (UNISINOS), a qual tem como objetivo analisar a internacionalização desde uma perspectiva crítica, que contemple a identidade e a realidade das universidades dos países latino-americanos. Neste sentido, a pesquisa tem foco no estudo das experiências da Universidade Federal para a Integração LatinoAmericana (UNILA), localizada em Foz de Iguaçu, Brasil, e da Escola Latino-americana de Medicina (ELAM), localizada em Havana, Cuba.

Partimos do pressuposto que na temática da internacionalização se desenvolve uma confrontação de duas perspectivas. A primeira, que poderíamos considerar como hegemônica, concebe a internacionalização como uma prática criada a partir da etapa da globalização neoliberal, guiada pelos rankings internacionais e pela comercialização da educação; e que acaba instalando este fenômeno da internacionalização na agenda das políticas educativas com a ajuda de organismos internacionais como o Banco Mundial (BM), a Organização para Cooperação e Desenvolvimento Econômico (OCDE) e a Organização Mundial do Comércio (OMC). A segunda perspectiva considera como necessária a construção de uma internacionalização baseada em valores que se encontram distantes da concepção da educação como um serviço que se pode vender e comprar. Portanto, a partir desta perspectiva se distinguem ações baseadas na reciprocidade, horizontalidade, complementaridade e solidariedade, como princípios para a vinculação internacional das universidades. 
Este trabalho se sustenta e fundamenta na segunda perspectiva, já que acreditamos na construção de um tipo de internacionalização contra-hegemônica, criada desde e para América Latina. Desde e para esta região para valorizar as experiências e o material teórico gerado sobre a internacionalização desde o "Sul", sendo um processo que responda e represente a nossa identidade e realidade local. Por isso, compreendemos que, para vincular-nos internacionalmente, temos que, primeiramente, conhecer-nos e conhecer o contexto no qual estão inseridas as nossas universidades, para logo realizar intercâmbios e trocas com outras culturas.

A organização do texto consta de quatro partes. Numa primeira, são analisadas diversas perspectivas da internacionalização da educação superior, detectadas mediante a revisão bibliográfica da pesquisa. Em segundo lugar, se caracteriza uma perspectiva em construção, baseada numa internacionalização desde e para América Latina. Num terceiro momento, serão apresentadas duas experiências de internacionalização inseridas dentro desta última perspectiva. Para isso, se realizou uma análise documental de relatórios, estatutos, regulamentos internos e planos de estudo das duas instituições que integram o escopo da pesquisa. Finalmente, serão expostas algumas considerações e reflexões sobre o que foi trabalhado ao longo do texto, bem como os principais desafios a serem enfrentados por estas duas instituições, no que diz respeito à promoção da internacionalização desde e para América Latina.

\section{Internacionalização da educação superior: perspectivas em torno da temática}

Desde a década de 1990, a internacionalização da educação superior se converteu numa temática de destacada importância a nível internacional, fazendo-se presente nas universidades junto com a tríade: ensino, pesquisa e extensão. A produção teórica sobre a internacionalização também foi acompanhando o desenvolvimento deste processo, primeiramente nos Estados Unidos, Canadá e Europa (KNIGHT, 1994; RUDZKI, 1998; TEICHLER, 1999; WIT, 1995), e logo, a partir de inicios do século XXI, na América Latina (DIDOU AUPETIT; ESCOBAR, 2014; GACÉL-ÁVILA, 2000; LAUS; MOROSINI, 2005; RINESI, 2013; TANGELSON, 2014).

Alguns interrogantes que guiaram estes estudos foram acerca do que é a internacionalização, através de que elementos se podem compreendê-la e quais seriam seus principais impactos. Levando em consideração estas perguntas, realizamos uma análise da produção teórica sobre a internacionalização e constatamos a existência de diversas classificações propostas por autores que, na maioria, confluem na existência de dois modelos de internacionalização da educação superior. Por um lado, um modelo baseado na lógica da mercantilização do ensino superior, guiado pelos organismos internacionais como a OMC, BM, OCDE, entre outros, que realizam uma forte aposta na comercialização da educação como um serviço lucrativo. O apoio teórico utilizado para este modelo é de autores como Silva (2002) e Imen (2005), que alertam sobre o papel destes organismos na educação, considerando-os 
como os novos mecanismos de doutrinamento e neocolonização sobre aqueles continentes que padeceram uma longa trajetória de colonização e subdesenvolvimento. Por outro lado, encontramos uma perspectiva que consegue ver, no processo de internacionalização, a necessidade de uma mudança institucional, de um giro dos protagonistas; isto é, de estudantes, de professores e gestores, para objetivos vinculados a cooperação entre iguais e a solidariedade regional. Alguns dos autores que auxiliam na construção de esta perspectiva são Didriksson (2008), López Segrera (2007), Rinesi (2013), Rojas Mix (2005) e Tangelson (2014), entre outros.

Apresentamos, a seguir, o Quadro 1, com as principais classificações dos autores sobre a internacionalização da educação superior.

Quadro 1. Classificações da Internacionalização da Educação Superior

\begin{tabular}{|l|l|l|}
\hline \multicolumn{1}{|c|}{ Autor(es) } & \multicolumn{2}{c|}{ Classificações da Internacionalização da educação superior } \\
\hline Knight (2005) & Cooperação Internacional vertical & Cooperação Internacional horizontal \\
\hline Morosinni (2011) & Modelo de internacionalização central & Modelo de internacionalização periférico \\
\hline Didriksson (2008) & Cooperação Internacional Tradicional & Cooperação Internacional horizontal \\
\hline López Segrera (2007) & Internacionalização lucrativa & Internacionalização solidaria \\
\hline Lima e Maranhão (2009) & Internacionalização Ativa & Internacionalização passiva \\
\hline Taborga et al. (2013) & Orientações de internacionalização exógenas & Orientações de internacionalização endógenas \\
\hline
\end{tabular}

Fonte: Elaborado pelas autoras com base nos aportes teóricos de autores citados.

O primeiro aporte teórico que podemos apontar é o realizado por Knight (2005), no qual descreve e classifica a cooperação internacional em vertical e horizontal. A cooperação vertical apoia-se em relações com uma hierarquização de doador-receptor, mediante a uma ajuda ou assistência do primeiro para com o segundo, enquanto que a cooperação horizontal desenvolve um benefício para ambas as partes, sobre a base de uma relação de sócio.

Por sua parte, Morosini (2011) destaca a existência de dois tipos de internacionalização, a saber, um modelo central e um modelo periférico. O primeiro deles incorpora a dimensão internacional, global e intercultural aos objetivos e funções universitárias, enquanto que no modelo periférico se encontram atividades internacionais em alguns setores das universidades. Da mesma maneira, Didriksson (2008) explora os modelos de internacionalização e os caracteriza por aqueles de cooperação internacional tradicional e horizontal. O primeiro modelo assenta-se em relações de competitividade entre as universidades por captar maiores projetos e alunos, denominados pelo autor como consumidores. Em relação ao segundo modelo proposto pelo autor, denominado cooperação horizontal, o 
mesmo baseia-se no fomento da cooperação solidária e o trabalho comunitário de redes e espaços comuns, sem perder a identidade de cada uma das instituições. Desta maneira, o modelo horizontal se apresenta como um espaço alternativo às lógicas hegemônicas, caracterizado pela transferência do valor social do conhecimento, a prioridade dos projetos conjuntos, a coparticipação dos recursos e a orientação social e solidária da educação. Outra contribuição é a de López Segrera (2007), que, em seu trabalho, propõe debater o dilema entre uma internacionalização lucrativa, com uma tendência à transnacionalização mercantilista, e uma internacionalização solidária, com base nos preceitos da educação superior como um bem público.

Já Lima e Maranhão (2009) propõem uma discussão de caráter conceitual entre uma internacionalização ativa e passiva. As autoras identificam que a primeira categoria se encontra majoritariamente presente nos "países centrais", como por exemplo, Estados Unidos, Reino Unido, Alemanha, França, Austrália e Canadá, devido a que estas nações implementam políticas de atração e recebimento de acadêmicos, como também oferecem serviços educacionais mais além das fronteiras geográficas do país, o qual envolve uma mobilidade de especialistas em determinadas áreas de interesse, a exportação de programas e a instalação de instituições no exterior. A internacionalização passiva é característica, principalmente, do que as autoras denominam países periféricos ou semiperiféricos, nos quais a situação a respeito à vinculação internacional universitária é diferente da que se manifestou nos países centrais.

Neste sentido, Lima e Maranhão (2009) consideram que, nos países periféricos ou semiperiféricos, não se encontra definida uma política de envio de acadêmicos ao estrangeiro, agravado pela reduzida capacidade que possuem estes países para oferecer condições atrativas de trabalho, uma vez finalizada a estadia. Ainda ressaltam as dificuldades em oferecer serviços educacionais no exterior, quando, segundo as autoras, estes países nem sequer respondem de maneira qualitativa e quantitativa a demanda interna. De acordo com esta última classificação, a internacionalização ativa gera as condições favoráveis para a emergência de uma internacionalização hegemônica, já que acontece em poucos países do mundo, no marco de uma crescente globalização hegemônica (DALE, 2004; SANTOS, 2002; TEODORO, 2003).

Outro escrito que podemos mencionar é o de Taborga et al. (2013), no qual se destaca a existência de dois tipos de orientações da internacionalização universitária, que condicionam seu maior ou menor desenvolvimento em determinadas regiões do mundo. Por um lado, se encontram as orientações exógenas, vinculadas à concepção da internacionalização sob a lógica de mercado e orientadas pelas agendas fixadas pelos organismos internacionais. Por outro lado, se desenvolvem orientações endógenas, seguidas por políticas nacionais e regionais que propõem uma visão autônoma e estratégica da internacionalização. Contrariamente às ideias de Lima e Maranhão (2009), o trabalho de Taborga et al. (2013) apresenta uma perspectiva da internacionalização que, longe de ser passiva, se manifesta com uma postura de resistência naqueles países que foram e que são atualmente colonizados por um pensamento 
hegemônico. Em consonância com estas afirmações, o argumento expõe a necessidade de gerar uma visão própria da internacionalização, que contemple as características e a idiossincrasia das universidades localizadas nestes países. Por este motivo, a comparação com os graus de desenvolvimento da internacionalização de universidade europeias ou estadunidenses não serviria para uma análise crítica e endogâmica da realidade da internacionalização universitária, por exemplo, na América Latina e no Caribe.

Como observamos nas classificações mencionadas, existe um tensionamento entre duas perspectivas de internacionalização que podemos resumir da seguinte forma: a) hegemônica e b) contra-hegemônica. Consideramos que a construção da segunda perspectiva representa um desafio para a região latino-americana, principalmente na concepção de uma internacionalização desde e para América Latina.

\section{Por uma internacionalização da educação superior desde e para a América Latina}

Um aspecto importante para começar a pensar e analisar uma internacionalização desde e para o cone Sul foi a constatação de que, ainda que se tenham incrementado, na última década, as produções sobre a temática realizada por pesquisadores latino-americanos, os especialistas desta região reconhecidos e citados por seus colegas são escassos (DIDOU AUPETIT; ESCOBAR, 2014). Deste modo, o referencial teórico utilizado para a análise do processo de internacionalização nas nossas universidades provém de um grupo de autores estrangeiros que representam o mainstream science da temática. Conforme assinala Mora-Osejo e Fals Borda (2006) e Rojas Mix (2005), não se trata de rejeitar a produção estrangeira das pesquisas, senão de analisá-la criticamente em função da realidade e dos problemas que afetam as universidades latino-americanas.

Neste sentido, esta perspectiva da internacionalização se nutre de uma demanda acadêmica em favor da realização de estudos endógenos (MORA-OSEJO; FALS BORDA, 2006), que trabalhem problemáticas autóctones do Cone Sul, através do conhecimento contextualizado por nossas realidades únicas e complexas. Assim, ao contrário da visão de construir definições neutrais e objetivas para implementar em realidades universais, surge a necessidade de realizar conceitualizações com um olhar a partir do Sul (SANTOS, 2009), a fim de criar um terreno fértil para o surgimento de um novo paradigma em outras latitudes. Essa discussão recupera um debate epistemológico sobre a superação de visões estrangeiras e o enriquecimento de um saber endógeno sobre os contextos da América Latina e do Caribe. De acordo com Mora-Osejo e Fals Borda (2006), é incompreensível que o quadro científico utilizado nos trabalhos de pesquisa não tenha uma raiz no ambiente em que se deseja aplicar e que, pelo contrário, utilize-se de ferramentas teórico-práticas disfuncionais para as características de nossas realidades. Portanto, é necessário construir um olhar 
endógeno que, como foi mencionado acima, não significa isolar-se da produção de conhecimento externo (ROJAS MIX, 2005,) senão que, em contraste, expressa a necessidade de uma acumulação de conhecimento proporcional ao crescimento e progresso das regiões para que logo seja contrastado e complementado com outras produções. Em suma, de acordo com Mora-Osejo e Fals Borda (2006, p. 715): "Os paradigmas fechados de outras partes conduzem frequentemente à castração intelectual no nosso meio e ao colonialismo intelectual".

Entendemos, assim que, para a análise de uma internacionalização da educação superior formulada desde e para a América Latina, devemos considerar algumas características ou seja:

a) localização e direcionalidade da internacionalização: Cooperação mais próxima à realidade dos países da América Latina, com uma direção prioritariamente Sul-Sul;

b) valores fundamentais: Solidariedade, cooperação, reciprocidade e complementariedade das ações no ensino superior;

c) lógicas do intercambio: Colaboração mútua, que inclua aspectos principalmente históricos, culturais e educacionais do processo de internacionalização e cooperação internacional das universidades no Sul do planeta;

d) perspectiva de análise e caraterísticas do material teórico: Busca de uma perspectiva crítica do processo de internacionalização da educação superior. Elaboração de conceitos, categorias e indicadores que respondam e representem a realidade das universidades latino-americanas.

Para explorar esta perspectiva de internacionalização, escolhemos, como campo empírico de pesquisa, duas instituições de ensino superior que, desde o início, foram pensadas a partir de uma lógica desde e para a América Latina: a Universidade Federal para a Integração Latino-Americana (UNILA) e a Escola Latino-Americana de Medicina (ELAM). A seguir serão apresentadas estas experiências de internacionalização da educação superior, com o objetivo de conhecer estas instituições, sua configuração e o trabalho que realizam.

\section{Universidade Federal para a Integração Latino-Americana}

O 12 de janeiro de 2010, foi sancionada pelo presidente brasileiro Luiz Inácio Lula da Silva a Lei no 12.189 que dispôs a criação da Universidade Federal para a Integração Latino-Americana (UNILA). A universidade começou suas atividades no segundo semestre de 2010, com 200 estudantes provenientes dos quatro países do MERCOSUL (ainda Venezuela se encontrava como estado associado ao bloco regional), que iniciaram seus estudos em seis cursos de graduação (UNILA, 2014). Desde sua criação, a universidade se localiza na cidade de Foz do Iguaçu, no Parque Tecnológico Itaipu (PTI), onde se ministram a maioria dos cursos da universidade. Outras unidades se encontram 
no Jardim Universitário, no edifício Rio Almada e na Unidade Administrativa - Vila A. Vale destacar que todas estas sedes são provisórias já que se está construindo um prédio, próximo ao PTI, que abrigará a futura sede da universidade, num terreno de 38 hectares doado pela Itaipu Binacional e projetado arquitetonicamente por Oscar Niemeyer.

Segundo o Estatuto da UNILA, sua missão (Art. 4ํㅜ) consiste em:

[...] contribuir para a integração solidária e a construção de sociedades na América Latina e Caribe mais justas, com equidade econômica e social, por meio do conhecimento compartilhado e da geração, transmissão, difusão e aplicação de conhecimentos produzidos pelo ensino, a pesquisa e a extensão, de forma indissociada, integrados na formação de cidadãos para o exercício acadêmico e profissional e empenhados na busca de soluções democráticas aos problemas latino-americanos (UNILA, 2012, p. 1).

Como pode se observar, na missão da universidade é salientado o seu papel como promotora da integração regional através de sua constituição como uma instituição sem fronteiras. Esta concepção também refletiu nas metas da universidade de se constituir como uma instituição bilíngue, com 500 professores e 10.000 alunos do Brasil e de outros países da América Latina, sendo o 50\% oriundos do Brasil e o outro 50\% da América Latina. Neste sentido, a integração com base na cooperação solidária impregna "toda a proposta pedagógica, seleção de professores, alunos e funcionários técnico-administrativos" (UNILA, 2014).

Quanto aos idiomas falados na UNILA, a universidade adota o português e o espanhol como línguas oficiais, destacando, como foi mencionado, o caráter bilíngue como uma ferramenta importante para a integração regional. Igualmente, se ofertam oficinas em Guarani para os estudantes que desejem aprender esta língua. A respeito da localização geográfica, se pode considerar que encontra-se próxima ao limite territorial de três países (Argentina, Brasil e Paraguai), sua posição é estratégica o que condiz com os objetivos e a missão da universidade em ser uma instituição internacional. No entanto, Schlogel (2013), alerta que o fato da UNILA estar localizada na tríplice fronteira não significa que as ações desta universidade se restrinjam aos limites territoriais dos três países.

Segundo dados do Departamento de Informações Institucionais (UNILA, 2014), os estudantes da América Latina matriculados na UNILA em 2014 representavam 11 nacionalidades latino-americanas, incluindo a brasileira. A seguir apresentamos um gráfico que contém o percentual de estudantes latino-americanos (sem contar o percentual de estudantes brasileiros) matriculados na universidade em 2014, junto com suas respectivas nacionalidades: 
Gráfico 1. Porcentagem de estudantes latino-americanos matriculados na UNILA (em 2014)

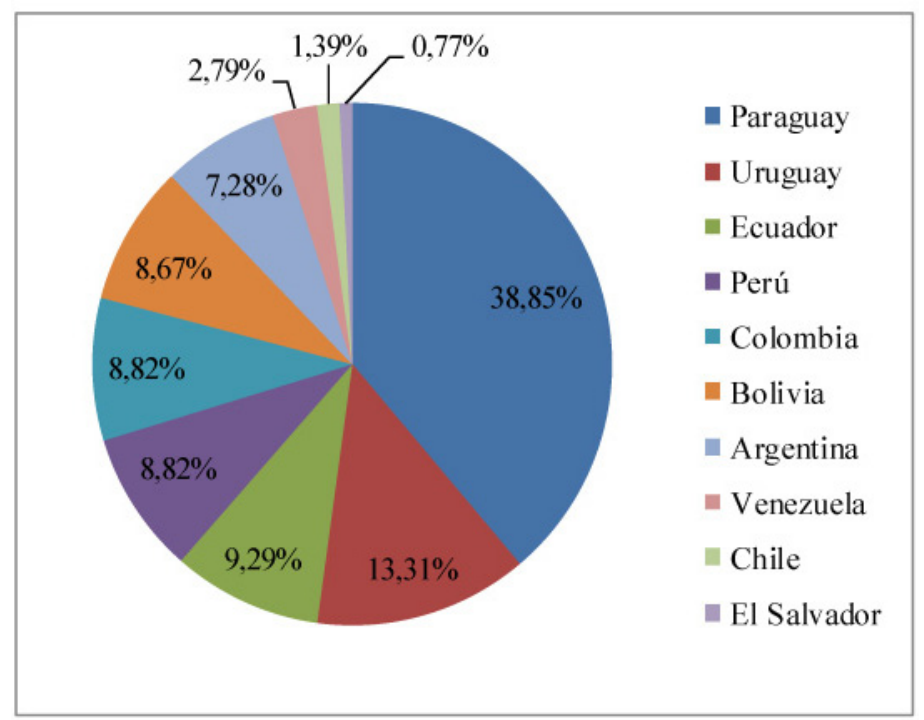

Fonte: Elaborado pelas autoras com base em dados do Departamento de Informações Institucionais da UNILA (UNILA, 2014).

Estas cifras, que datam do ano 2014, podem ser atualizadas com dados de 2015 e 2016. Neste sentido, no ano 2015, um grupo de mais de 80 estudantes haitianos chegaram a Foz de Iguaçu para realizar seus estudos na UNILA através do programa Pró-Haiti, que oferece vagas para imigrantes haitianos em 29 cursos desta universidade. Este programa forma parte da missão solidária que leva como estandarte a UNILA e inaugura o início da cooperação entre a UNILA e a região do Caribe. Frente a esta nova ponte de cooperação, o então reitor da universidade declarou: "Finalmente, chegamos ao Caribe, a uma nova fronteira, atingimos uma nova língua, o francês e o creole, nos abrimos cada vez mais para esta tão diversificada América Latina" (UNILA, 2014). Por outra parte, no início do ano letivo de 2016, foi ampliado o número de nacionalidades latino-americanas dos estudantes da UNILA para dezessete (17), incluindo a brasileira, devido à incorporação de estudantes provenientes de Costa Rica, Cuba, Guatemala, Panamá e República Dominicana. Assim, em 2016, o número total de estudantes matriculados na universidade é de 3.150, sendo: 2.050 alunos do Brasil e 1.100 oriundos de outros 16 países de América Latina (UNILA, 2016). 
Todos os anos, desde a criação da universidade, são ofertadas vagas em proporções iguais a estudantes brasileiros e estudantes oriundos de outros países da América Latina para que realizem cursos de graduação e, a partir do 2014, cursos de pós-graduação na UNILA. O processo seletivo destes grupos se realiza em língua portuguesa e em língua espanhola, atendendo a diversidade dos estudantes e ao objetivo da igualdade do acesso. Neste sentido, são realizados dois processos: um para os estudantes brasileiros e outro para os estudantes que provem de outros países latinoamericanos. Para o primeiro grupo, os estudantes ingressam mediante seu desempenho no Exame Nacional do Ensino Médio (ENEM) e, conforme alguns cursos como arquitetura e música, por meio da demonstração de habilidades específicas. A partir de 2014, a oferta de vagas para estudantes brasileiros ocorre através do Sistema de Seleção Unificada (SISU) do Governo Federal. Para o grupo de estudantes estrangeiros, a seleção é realiza "pelo Ministério da Educação ou órgão correlato dos seus países de origem e em 2012, foi instituída, pela Portaria no 407/2011, a comissão de composição internacional para conduzir este processo de seleção" (UNILA, 2015, p. 14). Da mesma forma, no Relatório de Autoavaliação Institucional de 2014 são especificadas duas modalidades de seleção para o grupo de estudantes estrangeiros (UNILA, 2015, p. 35-36):

[...] Seleção Direta: diretamente conduzida pela UNILA; aberta aos países da América Latina e Caribe, exceto o Brasil; nesta modalidade, não existe, para fins de classificação geral e final, a predeterminação de número de vagas por nacionalidade; não possui oferta de auxílios estudantis. Seleção Indireta: possui contrapartida financeira, na forma de auxílio estudantil aos estudantes, dos órgãos que firmaram acordos de cooperação com a UNILA; oferta de auxílio estudantil pela UNILA, de acordo com sua disponibilidade orçamentária e com a vulnerabilidade socioeconômica dos candidatos, obedecidos os termos da legislação brasileira.

Um aspecto importante para destacar da UNILA, relacionado ao anterior parágrafo, é a assistência estudantil oferecida aos estudantes estrangeiros que apresentam uma situação socioeconômica vulnerável. Este programa está composto por três itens: hospedagem, alimentação e transporte. O primeiro deles é para estudantes que provêm de outras localidades e que não tenham familiares residindo em Foz de Iguaçu. A partir desta condição, são oferecidas aos estudantes três opções, entre as quais se encontram um alojamento em quartos de diferentes prédios que são administrados por terceiros; alojamento em prédios próprios da universidade; e, finalmente, se encontra a opção de um subsídio financeiro mensal com a finalidade de alugar um imóvel individual ou grupal. O segundo item que conforma a assistência estudantil corresponde a uma quantia de dinheiro depositada todos os meses, em um cartão denominado "Nutricard", para que os estudantes possam comprar alimentos nos locais que aderem ao programa. O 
terceiro aspecto também consiste na entrega de um cartão que corresponde a dois vales-transportes por dia letivo do estudante.

Para aprofundar a reflexão sobre a UNILA, realizamos uma recopilação e posteriormente uma análise da produção científica e dos documentos institucionais. No estudo deste material podemos destacar duas características intrínsecas ao projeto universitário da UNILA, que se relacionam mutuamente: sua missão integracionista e seu caráter solidário. Sobre o primeiro deles, diversos autores (CORAZZA, 2010; COUTINHO, 2013; RICOBOM, 2010; SCHLOGEL, 2013; TRINDADE, 2009) destacam que esta universidade se constitui como um polo educativo intercultural que forma sujeitos com uma consciência latino-americana, capazes de contribuir com a resolução dos problemas que afetam a integração de nossa região. Para refletir sobre como a UNILA contribui para a integração regional, recorremos a dois fragmentos elaborados por duas professoras desta universidade em diferentes artigos acadêmicos. O primeiro deles destaca que:

No primeiro ano da graduação os alunos hispano falantes têm aulas de português e os alunos brasileiros têm aulas de espanhol. Também no primeiro ano, todos os alunos cursam uma disciplina chamada América Latina, independente da área de atuação do curso, com objetivo de contextualizar os alunos sobre o tema central da universidade (SCHLOGEL, 2013, p. 4).

No segundo fragmento, a autora também faz referência aos estudantes latino-americanos que ingressam a UNILA e como este fato se converte em uma das características mais importantes da universidade:

A UNILA é a primeira Universidade brasileira a receber, em nível de graduação e de forma proporcional ao número de alunos brasileiros, alunos estrangeiros de vários países latino-americanos. Os estudantes da UNILA compartilham não apenas os idiomas, mas suas experiências de vida, suas preferências culturais, os conhecimentos obtidos ao longo dos seus anos de estudos e o que é mais importante estarão em conjunto pensando o continente latino-americano (RICOBOM, 2010, p. 77).

Desta maneira, o caráter solidário da universidade também se converteu na pedra angular através da qual se construíram os alicerces da UNILA. Em um artigo acadêmico, o presidente da Comissão de Implantação da UNILA e primeiro reitor pro-tempore desta universidade afirmou que: "A UNILA está sendo instituída para promover, por intermédio do conhecimento e da cultura, a cooperação e o intercâmbio solidários com os demais países da região, aspiração histórica que se tornou imperativa nos dias atuais" (TRINDADE, 2009, p. 151). De acordo com ele, a solidariedade se tornou necessária na atualidade de nossos países, pelo qual a UNILA se conformou em torno dessa 
necessidade, adotando este valor como um aspecto intrínseco à instituição. Ademais, o autor amplia esta reflexão destacando que a missão da UNILA é e será "construir uma América Latina solidaria, em que a moeda de sua integração equitativa seja o conhecimento compartilhado, com respeito mútuo, em uma cultura de paz" (TRINDADE, 2009, p. 153).

Outro aspecto que surgiu das análises desenvolvidas na recopilação do material sobre a UNILA, foi a referência que realizam alguns autores sobre o papel da universidade frente ao conhecimento que se produz fora do contexto latino-americano, principalmente a tendência à europeização da ciência. Neste sentido, Martins (2011, p. 83) destaca que a "valorização da cultura latino-americana e a quebra do modelo tradicional de educação superior baseado em matrizes europeias são conceitos característicos do processo de implantação dessa instituição". Por outra parte, Ricobom (2010) afirma que o ensino na UNILA é fundamental para compreender outros sentidos da integração, que contemplem a multidimensionalidade dos fenômenos, proporcionando valor às identidades culturais e recepcionando, de maneira crítica, o conhecimento produzido fora de nossas regiões.

\section{Escola Latino-Americana de Medicina}

A criação da ELAM tem como pano de fundo uma tradição de cooperação e solidariedade internacional do povo cubano com as nações do mundo, que remonta aos inicios da revolução cubana e, também, a concepção que o pai da pátria cubana, José Martí, tinha da saúde e da medicina. Já sobre finais do século XIX, Martí tinha amadurecido uma sensibilidade sobre a medicina como uma profissão impregnada de humanismo e vocação.

Es la medicina como el derecho, profesión de lucha, necesítese un alma bien templada para desempeñar con éxito ese sacerdocio; el contacto de las diarias miserias morales y materiales, el combate con la sociedad y con la naturaleza, hacen mal a las almas pequeñas mientras que es revelación de cosas altas en almas altas y hermosas (MARTÍ, 1875 apud CEM, 2010, p. 203).

No parágrafo, a medicina é vinculada com a luta cotidiana dos médicos frente as misérias materiais e morais da sociedade, que afetam principalmente aos mais pobres. Neste sentido, Martí foi um precursor no estabelecimento de uma relação entre pobreza e doença, e um pioneiro em reclamar a responsabilidade do Estado (chamado por ele de Ayuntamiento) a respeito da saúde pública e das doenças que afetam à população. Estando no México, se deparou com uma realidade de pobreza e miséria, a qual se repetia em outros povos da Nossa América, essa pátria latino-americana que compartilhava uma história de saques, uma cultura diversa e um território rico em flora e fauna. Por isso, também 
em 1875, publica, na Revista Universal desse mesmo país, sobre o "estado tristísimo de la insalubre y abandonada ciudad de México" (MARTÍ, 1875 apud CEM, 2010, p. 172) e a responsabilidade do Estado em relação a isso.

Após a vitória do movimento revolucionário em 1959, foi instalado um governo de carácter socialista. Seu foco central foi o fortalecimento do Estado e sua intervenção em áreas prioritárias para o povo cubano, áreas estas que se encontravam deterioradas na iniciativa pública e elitizadas para o setor da burguesia e a aristocracia cubana. Assim, o Sistema de Saúde em Cuba se constituiu tendo por base a defesa de uma medicina de caráter estatal, social, humanista e internacionalista; medicina que se caracteriza pela atenção primária da saúde como parte de uma política pública, que tem como principais fundamentos a promoção, preservação, atenção, recuperação e reabilitação da saúde de toda a população. Estes avanços no âmbito da educação foram significativos para o desenvolvimento de ações de promoção da saúde e prevenção de doenças, junto com a execução de políticas públicas que assegurassem o aceso gratuito à saúde e aos serviços de atenção médica. Também, a princípios da década de sessenta, é iniciado o processo de colaboração internacional em matéria de saúde, por meio da criação da Brigada "Henry Reeves" em 1961, que se encontrava composta por um contingente de médicos para realizar uma atuação internacional, especializados em situações de desastres e epidemias graves. Algumas de suas atuações foram em Angola, Chile, Paquistão, Haiti, Guatemala e, mais recentemente (2014-2015), pode se mencionar seu trabalho na África para o combate ao ebola, bem como sua atuação no Nepal, para a atenção médica das vítimas afetadas pelo terremoto neste país.

Por isso, a criação da ELAM tem como pano de fundo este contexto histórico político, que se estende até finais do século XX, mais especificamente em 1998, ano em que dois furacões afetaram países Centro-americanos e o Caribe. Frente à catástrofe, Cuba elaborou um projeto de cooperação denominado "Programa Integral de Salud", que começou a funcionar com o envio de brigadas (compostas por trabalhadores da saúde) aos lugares mais afetados por estes fenômenos climáticos. Além disso, o programa ofertava bolsas de estudo para que estudantes dos povos afetados pelos furacões, para formarem-se como médicos em Cuba. Segundo o site da ELAM, "Es precisamente en ese contexto que el presidente cubano, Fidel Castro Ruz, concibió la creación de la ESCUELA LATINOAMERICANA DE MEDICINA (ELAM), para formar gratuitamente como médicos a jóvenes de esos países" (ELAM, 2015). Este objetivo inicial, logo foi estendido também à estudantes provenientes de outras regiões do mundo. Em 15 de novembro de 1999, no marco da IX Cúpula Ibero-Americana de Chefes de Estado e Governo, o presidente Fidel Castro anunciou a criação da Escola Latino-Americana de Medicina.

O prédio da ELAM se encontra localizado no município de Playa, a uns 25 quilômetros aproximadamente da cidade da Havana, Cuba. A instituição se localiza nas antigas instalações da Academia Naval "Granma”, do Ministério das Forças Armadas Revolucionárias, que foram cedidas ao Ministério da Saúde Pública para o funcionamento da ELAM. São mais de um milhão de metros quadrados, integrados em 28 prédios, com capacidade para hospedar mais 
de 3000 estudantes. Sobre os requisitos de ingresso, o Estado cubano realiza uma chamada anual, através das missões diplomáticas que se encontram em cada país, para que novos estudantes ingressem a ELAM. Quando os estudantes nela chegam, têm garantida a hospedagem, que ocorre no mesmo prédio da Academia Naval e que é compartilhado com outros estudantes, bem como a alimentação que é oferecida em um refeitório cinco vezes ao dia.

É necessário destacar que este projeto educativo foi criado fundamentalmente para estudantes que provêm de famílias com baixos recursos econômicos, destacando-se a procedência de estudantes da região latino-americana, caribenha e centro-americana. Dados proporcionados por Midalys Castilla, vice-reitora acadêmica da ELAM, numa entrevista em comemoração ao aniversário de 10 anos da instituição, destacam algumas características dos estudantes matriculados:

Nuestra matrícula actual es cercana a los 10.000 jóvenes. Hemos tenido ya cinco promociones (que concluyeron el programa de seis años) con 7.248 egresados de 28 países [...] En la actualidad estudian muchachos de 55 países -pues se incorporaron de países africanos y hasta de pequeñas islas del pacíficoy el 75\% de ellos son hijos de obreros y campesinos; además de estar representadas con becarios de 104 comunidades originarias de América Latina (MATRÍCULA..., 2010).

A diversidade e compromisso da ELAM também podem ser observados em outros dados, como, por exemplo, na Tabela 1, onde se encontram registrados os egressos da instituição por regiões, entre os anos 2005 e 2015.

Tabela 1. Total de graduados da ELAM por regiões (2005-2015).

\begin{tabular}{|c|c|c|c|c|c|c|c|c|c|c|c|c|}
\hline Regiões & 2005 & 2006 & 2007 & 2008 & 2009 & 2010 & 2011 & 2012 & 2013 & 2014 & 2015 & Total \\
\hline América do Sul & 494 & 582 & 689 & 741 & 760 & 834 & 791 & 4864 & 2853 & 141 & 725 & 13474 \\
\hline Centro América & 779 & 575 & 502 & 379 & 285 & 222 & 308 & 1210 & 718 & 1456 & 436 & 6870 \\
\hline Caribe & 222 & 159 & 101 & 246 & 129 & 135 & 201 & 145 & 180 & 397 & 175 & 2090 \\
\hline Eurásia & & & & & 6 & 26 & 65 & 412 & 318 & 332 & 606 & 1765 \\
\hline América do Norte & 1 & 38 & 69 & 100 & 98 & 84 & 75 & 78 & 458 & 142 & 126 & 1269 \\
\hline África & & 89 & 186 & 73 & 34 & 20 & 129 & 30 & 25 & 317 & 197 & 1100 \\
\hline Oceania & & & & & & & & & 16 & 23 & 50 & 89 \\
\hline Total & 1496 & 1443 & 1547 & 1539 & 1312 & 1321 & 1569 & 6739 & 4568 & 2808 & 2315 & 26657 \\
\hline
\end{tabular}

Fonte: Escola Latino-Americana de Medicina (2015). 
Podemos perceber, pelos dados, que a primeira região em número de egressos da ELAM é a América do Sul, seguida de Centro América e o Caribe. Logo se encontra Eurásia (que é a zona geográfica que compreende o continente Europeu com Ásia), com graduados em medicina a partir do ano 2009, América do Norte, África e Oceania. Neste sentido, também destacamos que, na formação da ELAM, encontram-se representados os cinco continentes, sem contar a Antártida.

Essas cifras revelam uma grande heterogeneidade, que caracteriza o projeto da ELAM e o faz particular. Também forma parte desta particularidade o compromisso de formar estudantes de famílias de baixos recursos, pertencentes a regiões que foram, historicamente, mais postergadas; estudantes que provêm de uma multiplicidade de grupos éticos como os mapuches da Argentina, os aimaras e kechuas da Bolívia, Ngobe e Kuma de Panamá, Kiche e Kagchikei de Guatemala, entre outros (ELAM, 2011).

Sobre a formação dos estudantes, o único curso que é oferecido na ELAM é o de medicina, que tem uma duração de seis anos, onde os estudantes se formam como médicos com orientação a um trabalho de Atenção Primária da Saúde. O curso começa com uma primeira etapa para os estudantes ingressantes, chamada "pré-médico", que se realiza no prédio da ELAM, tem uma duração de 24 semanas e cumpre com o objetivo de diagnosticar a situação acadêmica e as características gerais do ingressante. Neste processo também se inclui a formação em diversas matérias básicas para o nivelamento dos alunos. Para os estudantes que não são hispano-falantes é oferecido um curso de língua espanhola, antes de realizar o pré-médico e também durante esta primeira etapa. Logo vem a etapa do "ciclo básico", que tem a duração de um ano e meio e também se realiza na ELAM. A partir do terceiro ano, encontramos o "ciclo clínico", onde os estudantes se deslocam até outras províncias de Cuba (em total 14), ou na própria Havana, para continuar seus estudos nas diferentes universidades e faculdades de medicina do país, e para realizar suas práticas nos serviços hospitalares e centros de saúde. O último ano, o sexto, finaliza com um "internado rotatório", onde o estudante põe em prática os princípios da ciência sócio-biológica e transforma as informações e habilidades adquiridas em modos e práticas de atuação. São realizadas cinco rotações por diversas áreas como a medicina, pediatria, cirurgia, ginecologia e medicina geral integral. Esta etapa finaliza com a aplicação de um exame final estatal teórico e prático, que comprove as competências profissionais, no qual o estudante deve ser aprovado para se graduar no curso. Além disso, segundo o plano de estudos da carreira: "Para concurrir al Examen Estatal, el educando debe haber aprobado, mediante exámenes prácticos y teóricos, las 5 rotaciones del Internado" (UNIVERSIDAD DE CIENCIAS MÉDICAS DE LA HABANA, 2015).

Nesta formação, uma característica que sobressai, além da diversidade, é a importância que outorga a instituição ao vínculo universidade-sociedade. Conforme o Catálogo Institucional da ELAM 2011, as ações de extensão "están orientadas al intercambio cultural entre las distintas naciones representadas en la Institución y la interrelación con la cultura cubana, aprovechando el tronco común de una raíz cultural de origen afín” (ELAM, 2011, p. 46). 
É importante salientar que a vocação internacionalista, a formação em valores solidários e humanistas, o compromisso com a realidade social, a diversidade, e outras características da ELAM, se encontram inscritas na missão da instituição, a qual propõe:

[...] formar Médicos Generales Básicos, orientados hacia la atención primaria de salud como escenario fundamental de su atención profesional, con una elevada preparación científica, humanista, ética y solidaria; capaces de actuar en su entorno de acuerdo con las necesidades de la región para el desarrollo humano sostenible. (ELAM, 2015).

Tudo isto, como foi mencionado na contextualização da ELAM, também tem a contribuição do pensamento de José Martí. Por isso, não é casualidade que na entrada principal da ELAM, os primeiros quadros pendurados na parede sejam os de José Martí e Simón Bolívar, ao lado de todas as bandeiras dos países dos estudantes e graduados da instituição. Este cenário representa um trabalho coletivo e colaborativo que transcende as fronteiras, visando responder as necessidades e problemáticas da Nossa América, de José Martí, e da "Patria Grande", de Simón Bolívar. Segundo o cubano, a pátria era algo mais que uma terra em particular ou uma possessão tomada pela força. Para ele "Patria es humanidad, es aquella porción de la humanidad que vemos más de cerca, y en que nos tocó nacer" (MARTI, 1895 apud BATLE, 2013, p. 292), e é sob esta concepção que a ELAM forma médicos de diversas nacionalidades para realizar um trabalho humano comprometido com a realidade de seus países e a de outros que estejam necessitando colaboração em matéria de saúde.

\section{Considerações finais}

Esta pesquisa continua seu caminho, aberto com a investigação que tem, como campo empírico, duas instituições localizadas em realidades completamente diferentes, mas com um objetivo em comum: o crescimento e fortalecimento de um espaço que contribua para a criação de um olhar latino-americano, um olhar que contemple as particularidades de uma região com uma composição social multiétnica. Um olhar que responda às problemáticas que afetam ao meio no qual se encontram, mas, sobretudo, que construa conhecimento sem imposições estrangeiras. Neste sentido, retomando o pensamento de Martí, consideramos que para chegar à verdadeira independência, é preciso gerar um conhecimento próprio e ensinar quais são os problemas que afetam aos países da região, tendo como meta a unidade e a integração dos povos de Nossa América. 
Entendemos que este caminho não se encontra fora de desafios e dificuldades para aqueles que quiserem percorrê-lo. Tanto a UNILA quanto a ELAM enfrentam diversos problemas para conseguir cumprir os objetivos que deram nascimento a seus projetos institucionais. No caso da UNILA, podemos nos perguntar quais as principais problemáticas nacionais e regionais que enfrenta a universidade para desenvolver-se como um polo de integração latino-americana? Da ELAM, surge a pergunta sobre como se cria e se desenvolve uma instituição educativa, que tem como objetivo formar médicos em Cuba de diversas nacionalidades de maneira solidária e gratuita, num contexto no qual existe um bloqueio econômico, comercial e financeiro por parte de Estados Unidos há mais de 50 anos, que dificulta a vida cotidiana do povo cubano?

No entanto, os documentos e a produção teórica sobre estas instituições demonstram que essas experiências se constituíram e ainda hoje se constituem sob valores solidários, cooperativos e integracionistas. Por isso, a UNILA e a ELAM expressam que a busca de outro olhar e outra lógica de internacionalização é possível, no atual cenário hegemônico de internacionalização da educação superior, caracterizado pelos rankings internacionais, pela competitividade e pela venda de serviços educativos. Assim, esta perspectiva de internacionalização crítica e contra-hegemônica vai se construindo e consolidando através de experiências como estas, que são pensadas desde e para a América Latina.

\section{Referências}

CORAZZA, G. A Unila e a integração latino-americana. Boletim de Economia e Política Internacional, São Paulo, n. 3, p. 79-88, jun. 2010.

COUTINHO, C. S. Missão integracionista da Unila. In: SARTI, I. et al. (Org.). Por uma integração ampliada da América do Sul no século XXI. Rio de Janeiro: PerSe, 2013. v. 2, p. 879-894. Disponível em: <http://www.fomerco.com.br/conteudo/view?ID CONTEUDO=237>. Acesso em: 11 abr. 2014.

DALE, R. Globalização e educação: demonstrando a existência de uma 'cultura educacional mundial comum' ou localizando uma 'agenda globalmente estruturada para a educação. Educação \& Sociedade, Campinas, v. 25, n. 87, p. 423-460, 2004.

DIDOU AUPETIT, S.; ESCOBAR V. J. (Coord.) Internacionalización de la educación superior y las ciencias en América Latina: un Estado del arte. Mendoza, Argentina: Observatorio de Movilidades Académicas y Científicas del IESALC-UNESCO: Editorial de la Facultad de Filosofía y Letras de la Universidad Nacional de Cuyo. 2014.

DIDRIKSSON, A. Contexto global y regional de la educación superior en América Latina y el Caribe. In: IESALC. Tendencias de la educación superior en América Latina y el Caribe. Caracas: IESALC-UNESCO, 2008.

ESCOLA LATINOAMERICANA DE MEDICINA (ELAM). Cuba, 2015. Disponível em: <http://instituciones.sld.cu/elam>. Acesso em: out. 2015.

Educação Por Escrito, Porto Alegre, v. 7, n. 2, p. 181-200, jul.-dez. 2016 
ESCOLA LATINOAMERICANA DE MEDICINA (ELAM). Catálogo institucional da Escuela Latino-Americana de Medicina. Havana, Cuba, 2011.

GACEL-ÁVILA, J. La internacionalización de las universidades mexicanas. Políticas y estratégias institucionales. Anuies, México, 2000.

IMEN P. La escuela pública sitiada. Crítica de la transformación educativa. Buenos Aires: Centro Cultural de la Cooperación Floreal Gorini, 2005.

KNIGHT, J. Internationalization: elements and checkpoints. Otawa: Oficina de Canadá para la Cooperación Internacional, 1994. (Monografía investigativa, n. 7).

LAUS, S.; MOROSINI, M. Internacionalización de la educación superior em Brasil. In: WIT, H. et al. (Ed.). Educación superior en América Latina. La dimensión Internacional. Bogotá: Banco Mundial: Mayol Ediciones, 2005.

LIMA, M. C.; MARANHÃO, C. M. S. O sistema de educação superior mundial: entre a internacionalização ativa e passiva. Avaliação, Campinas, v. 14, n. 3, p. 583-690, 2009.

LÓPEZ SEGRERA, F. Educación superior: reforma y prospectiva. ¿Internacionalización o transnacionalización? In: LEAL, M. A. N.; RODRÍGUEZ, I. S. Transformación mundial de la educación superior. México, Universidad Iberoamericana de Puebla, 2007. p. 13-60.

MARTÍ, J. Boletín. El Ayuntamiento. Revista Universal. México, 4 de setembro de 1875. In: CENTRO DE ESTUDOS MARTIANOS (CEM). Obras Completas. 3. ed. Havana: Centro de Estudos Martianos, 2010. t. 2, p. 172-174.

MARTí, J. Pátria. In: BATLE, Jorge Sergio (Org.). José Martí: aforismos. Havana: Centro de Estudos Martianos (CEM), 2013. p. 292.

MARTINS, D. V. A história da educação superior na América Latina e o desafio integracionista da Universidade Federal da Integração Latino-americana (UNILA). 2011. 96 f. Dissertação (Mestrado em Educação) - Programa de Pós-Graduação em Educação, Universidade Estadual do Oeste do Paraná (UNIOESTE), Foz do Iguaçu, 2011.

MATRÍCULA de la Escuela Latinoamericana de Medicina en Cuba llega a los 10000 estudiantes. Cubadebate, Sitio Web de la Universidad de las Ciências Informáticas - UCI, La Habana, Cuba, 16 mar. 2010. Disponível em: <http://www.cubadebate.cu/ noticias/2010/03/16/matricula-de-la-escuela-latinoamericana-de-medicina-en-cuba-llega-a-los-10-000-estudiantes/\#.Vpj-hyCrTeS>. Acesso em: 10 ago. 2015.

MORA-OSEJO L.; FALS BORDA, O. A superação do eurocentrismo. Enriquecimiento do saber sistémico e endógeno sobre o nosso contexto tropical. In: SANTOS, B. S. (Org.). Conhecimento prudente para uma vida decente: "um discurso sobre as ciências" revisitado. São Paulo: Cortez, 2006.

MOROSINI, M. C. Internacionalização na produção de conhecimento em IES Brasileiras: cooperação internacional tradicional e cooperação internacional horizontal. Educação em Revista, Belo Horizonte, v. 27, n. 1, p. 93-112, 2011. Disponível em: <http://www. scielo.br/scielo.php?pid=S010246982011000100005\&script=sci_arttext $>$. Acesso em: 13 abr. 2013.

RICOBOM, G. UNILA: a contribuição do ensino para a integração da América Latina. Revista do Centro de Educação e Letras, Foz do Iguaçu, v. 12, n. 1, p. 67-78, 2010. 
RINESI, E. (Coord.). Ahora es cuando: internacionalización e integración regional universitaria en América Latina. Los Polvorines: Universidad Nacional de General Sarmiento, 2013.

ROJAS MIX, M. Siete preguntas sobre la Universidad Latinoamericana del siglo XXI. In: PUGLIESE, J. C. (Ed.) Educación superior: bien público o bien de mercado. Buenos Aires: Ministerio de Educación, Ciencia y Tecnología; Secretaría de Políticas Universitarias, 2005.

RUDZKI, R. The strategic management of internationalization-towards a model of theory and practice. 1998. Doctoral thesis School of Education, University of Newcastle upon Tyne, Newcastle, 1998.

SANTOS, B. S. Epistemologías del Sur. México: Siglo XXI Editores, 2009.

SANTOS, B. S. Os processos da globalização. In: SANTOS, B. S. (Org.). Globalização: fatalidade ou utopia? 2. ed. Porto: Afrontamento, 2002.

SCHLOGEL, D. A. O projeto da Universidade Federal da Integração Latino-Americana (UNILA). Revista Congreso Universidad, [S.1.], v. 2, n. 3, p.1-7, 2013.

SILVA, M. A. Política educacional do Banco Mundial entre 1970 e 1996 . In: SILVA, M. A. Intervenção e consentimento: a política educacional do Banco Mundial. Campinas: Autores Associados; São Paulo: Fapesp, 2002.

TABORGA, A. M. et al. La Internacionalización de la universidad en Argentina a principios del siglo XXI: desde una "orientación exógena" hacia una "orientación endógena. In: MARTÍNEZ, M. E.; PIÑERO, F. J.; DELGADO, S. A. El papel de la universidad en el desarrollo. Puebla: Universidad Autónoma de Puebla; Bueno Aires: Universidad Nacional del Centro de la Provincia de Buenos Aires, 2013.

TANGELSON, G. Desde el sur: miradas sobre la internacionalización. Lanús, Buenos Aires: Ediciones de la UNLa - Universidad Nacional de Lanús, 2014.

TEICHLER, U. Internationalisation as a challenge for higher education in Europe. Tertiary Education and Management, v. 5, n. 1, p. 5-22, 1999.

TEODORO, A. Globalização e educação: políticas educacionais e novos modos de governação. São Paulo: Cortez, 2003.

TRINDADE, H. UNILA: Universidade para a integração latino-americana. Revista Educación Superior y Sociedad/Nueva Época, v. 14, n. 1, p. 147-153, 2009.

UNIVERSIDAD DE CIENCIAS MÉDICAS DE LA HABANA Síntesis del plan de estúdios de la carrera de medicina. Habana: Cuba, [2015?]. Disponível em <http://instituciones.sld.cu/ucmh/estudios-academicos-autofinanciados/sintesis-del-plan-de-estudio-dela-carrera-de-medicina>. Acesso em: ago. 2015.

UNIVERSIDADE FEDERAL DA INTEGRAÇÃO LATINO-AMERICANA (UNILA). Foz de Iguaçu, 2014. Disponível em: < http:// www.unila.edu.br>. Acesso em: 10 ago. 2014.

UNIVERSIDADE FEDERAL DA INTEGRAÇÃO LATINO-AMERICANA (UNILA). Foz de Iguaçu, 2016. Disponível em: <http:// www.unila.edu.br>. Acesso em: jun. 2016. 
UNIVERSIDADE FEDERAL DA INTEGRAÇÃO LATINO-AMERICANA (UNILA). Comissão Própria de Avaliação (CPA). Relatório de autoavaliação institucional 2014. Foz do Iguaçu, 2015.

UNIVERSIDADE FEDERAL DA INTEGRAÇÃO LATINO-AMERICANA (UNILA). Estatuto. Foz do Iguaçu, 2012.

WIT, H. Strategies or internationalization of higher education: a comparative study of Australian, Canada, Europe and United States. Ámsterdam: Asociación Europea para la Educación Internacional, 1995.

Recebido em: agosto/2016

Aceito em: novembro/2016

\section{Endereco para correspondência:}

Maria Julieta Abba

Programa de Pós-Graduação em Educação

Avenida Unisinos, 950 - Prédio B09, 4ํaa andar - Bairro Cristo Rei

93022-750 São Leopoldo, RS, Brasil

<mjulieta.abba@gmail.com> 